\title{
Selfish learning: the impact of self-referential encoding on children's literacy attainment
}

David J. Turk, Karri Gillespie-Smith, Olave E. Krigolson, Catrion Havard, Martin A. Conway and Sheila J. Cunningham

This is the accepted manuscript (C) 2015, Elsevier

Licensed under the Creative Commons Attribution-NonCommercialNoDerivatives 4.0 International http://creativecommons.org/licenses/bync-nd/4.0/

(c)) EY-NC-ND

The published article is available from doi:

10.1016/j.learninstruc.2015.08.001 
Self-referential encoding in learning

RUNNING HEAD: Self-referential encoding in learning

Selfish learning: The impact of self-referential encoding on children's literacy

attainment 


\begin{abstract}
Self-referencing (i.e., thinking about oneself during encoding) can increase attention toward to-be-encoded material, and support memory for information in adults and children. The current inquiry tested an educational application of this 'self reference effect' (SRE) on memory. A self-referential modification of literacy tasks (vocabulary spelling) was tested in two experiments. In Experiment 1, seven- to nineyear-old children $(N=47)$ were asked to learn the spelling of four nonsense words by copying the vocabulary and generating sentences. Half of the children were asked to include themselves as a subject in each sentence. Results showed that children in this self-referent condition produced longer sentences and increased spelling accuracy by more than $20 \%$, relative to those in an other-referent condition. Experiment $2(N=32)$ replicated this pattern in real-word learning. These findings demonstrate the significant potential advantages of utilizing self-referential encoding in the classroom.
\end{abstract}

Keywords: self, memory, literacy, engagement, attention 


\section{Introduction}

Psychological science plays an important role in teaching practice, with cognitive theory underpinning a variety of learning strategies (Pressley, Borkwski, \& Schneider, 1989). For example, learners are more likely to retain information successfully when they are engaged with the learning materials and the information is richly encoded, so materials that promote these elements comprise valuable learning tools (Fredricks, Blumenfeld, \& Paris, 2004; Sadoski, 2001). In line with this reasoning, the current report investigates the application of a robust memory phenomenon known as the self-reference effect (SRE - Rogers, Kuiper, \& Kirker, 1977), assessing its usefulness in promoting children's literacy engagement and learning.

Standard cognitive accounts of memory processing such as dual-coding (Paivio, 1986) and levels of processing (Craik \& Lockhart, 1972) suggest that rich encoding (e.g., that which promotes interconnectivity with current knowledge) is key to improving learning (for review see Sadoski, 2001). Consistent with this argument, Sadoski and colleagues demonstrated that both concreteness and familiarity are highly predictive of text learning, arguing that these features evoke rich verbal and nonverbal processing (Sadoski, Goetz, \& Fritz, 1993; Sadoski, Goetz, \& Rodriguez, 2000). Based on these findings, Sadoski (2001) suggests that educators include concrete, image-evoking features like personal hobbies and cartoon characters in children's learning materials to promote rich encoding. However, it is clear that teachers cannot reasonably be expected to create personally interesting materials for each child. A potential solution to this challenge it the use of a ubiquitous and highly reliable character with which to engage children and enhance learning: themselves. 


\subsection{The self and memory}

Thinking about oneself while encoding information (known as 'selfreferencing') is well-established in the psychological literature as a method of increasing retention in memory (e.g., Conway \& Dewhurst, 1995; Klein \& Kihlstrom, 1986; Klein \& Loftus, 1988; Rogers et al., 1977; Symons \& Johnson, 1997; Turk, Cunningham, \& Macrae, 2008). The memory advantage associated with selfreferencing is known as the 'self-reference effect' (SRE). The SRE can be elicited through surprisingly simple self-item associations, for example by presenting to-beremembered information simultaneously with the participant's own name or face (Turk et al., 2008), by assigning items to self through temporary ownership (Cunningham, Turk, MacDonald, \& Macrae, 2008) or through self-choice (Cunningham, van den Bos, \& Turk, 2011). Several studies have also demonstrated robust SREs in early and middle childhood (Cunningham, Brebner, Quinn, \& Turk, 2014; Cunningham Vergunst, Macrae, \& Turk, 2013; Ross, Anderson, \& Campbell, 2011; Sui \& Zhu, 2005).

The features of self-referencing are notably consistent with Sadoski's (2001) recommendations for educational materials, namely familiarity and concreteness. Even in early childhood there is a highly developed sense of self that is frequently accessed and richly furnished with concrete knowledge (Lewis, 2003), as well as being self-evidently familiar. The self-concept has been argued to underlie the SRE, supporting the high levels of elaboration and organization associated with selfreferential memories (Klein \& Kihlstrom, 1986; Klein \& Loftus, 1988; Symons \& Johnston, 1997). The support of the self-knowledge framework in memory should 
therefore allow educational materials encoded in a self-referential context to be more successfully retained.

A second, highly valuable cognitive consequence of evoking the self at encoding is that it triggers mechanisms that could enhance task engagement. Specifically, cues of self-relevance such as one's own face or name provoke automatic shifts in attention and increased affective arousal, changes which both have a significant positive effect on memory (Turk et al., 2008; Turk, van Bussel, Brebner, Toma, Krigolson, \& Handy, 2011). Engagement is a particularly important element of teaching practice, and indeed the erosion of interest and academic motivation as education progresses has been the source of a number of empirical studies (see Eccles, Wigfield, \& Schiefele, 1998; Wigfield, Eccles, Schiefele, Roeser, \& DavisKean, 2006).

It has been suggested that academic progress is facilitated by three types of pupil engagement: cognitive, emotional and behavioural (Christenson et al., 2012; Fredericks et al., 2004). Tasks that maximize these three inter-related components of academic engagement, such as agentic engagement, positively influence academic outcomes (Reeve, 2013). The increased attentional allocation, positive affect and enhanced cognitive performance associated with self-referential encoding would seem to fit well with this tripartite understanding of academic engagements, suggesting that self-referencing could influence levels of student engagement.

Supporting this contention, some evidence for enhanced processing under conditions of self-referencing in education has been reported in the context of mathematics. D'Ailly, Simpson and MacKinnon (1997) showed that for relational word problems (e.g., John has four sweets. James has two more sweets that John. How many sweets does James have?) there was a significant improvement in both 
speed and accuracy following the inclusion of a self-referential term (e.g., John has four sweets. You have two more sweets that John. How many sweets do you have?). Such improvements may reflect an increase in task engagement (Davis-Dorsey, Ross, \& Morrison, 1991; Fairbairn, 1993; Giordano, 1990; Hart, 1996).

Drawing these arguments together, a logical prediction is that embedding selfreferencing strategies in educational materials could fulfill both of Sadoski's (2001) key criteria of effective teaching strategy: promoting rich encoding and increasing engagement in learning. The current study will assess this prediction in the context of literacy education.

\subsection{Self-referencing in literacy}

Some extant research supports the contention that self-referencing could successfully be applied in a literacy context. For example, children are generally able to write and spell their own names before other words (Levin, Both-de Vries, Aram, \& Bus, 2005), and show a marked preference for including (often erroneously) letters from their own name when writing other words (Bloodgood, 1999; Both-de Vries \& Bus, 2008; Treiman, Kessler, and Bourassa, 2001). The early focus on own-name letters, particularly the name's first letter, has been attributed to increased sensitivity to this sound-letter combination (e.g., Both-de Vries \& Bus, 2010). It is also likely to reflect the extreme familiarity and positivity associated with one's own name (i.e., the 'name-letter effect' - Nuttin, 1985).

Other studies purporting to test a self-referential bias in literacy have reported conflicting results. Pressley, Levin, Kuiper, Bryant, and Michener (1982, Exp. 2) report a deleterious effect of employing self-referential encoding relative to a 
keyword imagery strategy in adults' learning of new words. However, Mood (1979) showed that sentence comprehension in very young children $(2-5$ year olds) was significantly improved by inclusion of a self-referential material (i.e., the child's own name). The differences in methodology across these studies (particularly regarding control conditions) is too great to allow firm conclusions to be drawn from the mixed findings, but it is possible that self-referential encoding strategies are best targeted at an early developmental period. Given the equivocal findings reported in these studies, further investigation of the efficacy of self-referential learning strategies is clearly warranted.

\subsection{The current inquiry}

The current investigation explored whether self-referential encoding could enhance pupil engagement and performance in learning to spell. Experiments were based on a typical literacy task known as the 'See it, Say it, Cover it, Write it, Check it and Write a Sentence' (SSCWC-WS) method, which involves children copying tobe-learned words then including them in a self-generated sentence. The current study evaluated the impact of a self-referential version of this task on pupil engagement and attainment in two experiments, examining novel nonsense- and real-word learning respectively.

\section{EXPERIMENT 1}

This experiment employed four nonsense words presented to pupils as the names of novel alien characters. These materials were used to reduce the effects of prior knowledge on learning outcomes. Children's task engagement was gauged by 
measuring the length of sentences they generated, as motivation to generate long sentences should be reduced by low engagement (see Meece, Blumenfeld, \& Hoyle, 1988; Newmann, Wehlage, \& Lamborn, 1992; Reeve, 2013). Behavioural engagement was objectively measured using mean sentence length in words as an index of the child's motivation to engage with the learning task. Other measures of behavioural engagement could also be applied, such as the morphemic complexity of sentences produced, but research indicates that these two measures are almost perfectly correlated (e.g., Brown, 1973; Parker, 2005) and therefore we have favoured the simple method in our assessment of task engagement in this study.

Subsequent spelling accuracy was measured to assess learning success. It was predicted that self-referential encoding would result in longer sentence generation and higher spelling performance than other-referential encoding.

\subsection{Method}

\subsubsection{Participants and design}

Forty-seven primary school children aged between 86 months and 108 months (M: 97.23 months, $S D: 6.44,27$ females) were tested in a between-subjects design with a single factor of Referent (Self or Other). The children were recruited from one Year 4 class in three different Aberdeenshire primary schools. Given the task requirement to process novel non-words we first measured the performance of every child on the Children's Nonword Repetition (CNRep) Test which provides a measure of phonological processing abilities on nonsense words (Gathercole, Willis, Baddeley \& Emslie, 1994). We then assigned children to experimental conditions so that each group was matched on CNRep score $t(45)=.46, p=.65$ and on age in months; $t(45)=$ $.79, p=.44($ see Table 1$)$. 


\subsubsection{Materials and Procedure}

Four two-syllable nonsense words were presented as the names of green aliens (Arror, Genful, Winead \& Swarty). An additional red alien (Splay) was created as a neutral other-referent. The experimenter used color images printed on cards to introduce each alien to the children (see supplementary figure), who then copied all four names twice. Children were then asked to write a sentence describing an imaginary day for each alien, including either self (e.g., 'Arror and I went to...') or the other-referent (e.g., 'Arror and Splay went to...') as a subject depending on experimental condition. Once each child in the group had finished their four sentences, the Experimenter enunciated the four alien names one at a time, and the children were asked to write the names on a worksheet, concentrating on the spelling.

\subsection{Results and Discussion}

Copying accuracy was high on this task ( $1.8 \%$ error). As a result, all children were included in subsequent analyses. For illustration, sentences produced by participants in the self- and other-referent conditions are listed below:

\section{Participant A (self-referent condition), aged 105 mths}

On Monday me and Genful did science.

Participant B (self-referent condition), aged 105 mths

Me and Winead went to decorate a plate at Dab Hand.

Participant C (self-referent condition), aged 88 mths

Me and Arror like to swim. 
Participant D (self-referent condition), aged 93 mths

On Friday me and Swarty dressed up as a nasty wizard.

Participant F (other-referent condition), aged 106 mths

Genful would turn Splay into a mosquito.

Participant E (other-referent condition), aged 87 mths

Winead likes to do art with Splay.

\section{Participant F (other-referent condition), aged 100 mths}

Splay and Arror went swimming in the sea and had lots of fun.

Participant F (other-referent condition), aged 93 mths

Swarty would teach him how to do magic.

For each child, the number of words generated in the sentence production task was calculated (mean length utterance in words) ${ }^{1}$. A spelling score was also calculated by assigning one mark for each correctly spelled name. Descriptive data are presented in Table 1. Following the suggestion of an anonymous reviewer, we included "alien name" in our statistical model to take account of any differences across each of the tobe-learned items. Two models were generated to explore word generation effects and spelling accuracy. The mixed model ANOVA exploring the effect of encoding condition on the number of words written across each alien name revealed a no significant main effect of alien name $\mathrm{F}(3,135)=.67, p=.571$, see table 1 for means).

\footnotetext{
${ }^{1}$ As suggested earlier, this score elicited an almost perfect correlation with number of morphemes produced $\mathrm{r}(47)=.94, \mathrm{p}<.001$.
} 
Additionally, alien name did not significantly interact with encoding condition $\mathrm{F}(3,135)=.191, p=.903$. The only significant effect observed was that children in the self encoding condition wrote significantly more words than those in the other encoding condition $\mathrm{F}(1,45)=5.79, p=.02$, Cohen's $\mathrm{d}=.83$ representing a large effect (see Table 2).

A second statistical model exploring differences in spelling accuracy revealed a no significant main effect of alien name $\mathrm{F}(3,135)=7.62, p<.001$, see table 1 for means). Additionally, alien name did not significantly interact with encoding condition $\mathrm{F}(3,135)=.407, p=.748$. The only significant effect observed was that children in the self encoding condition correctly spelled more words than those in the other encoding condition $\mathrm{F}(1,45)=7.581, p<.005$, Cohen's $\mathrm{d}=.65$, suggesting a medium to large effect (see Table 2). Post-hoc pairwise comparisons of the main effect of alien name across self and other encoding conditions, corrected for multiple comparisons using the Bonferroni method were then carried out. This analysis showed that the name Winead was spelled less accurately than Genful $(\mathrm{p}=.002)$ and Arror $(\mathrm{p}<.004)$. Most importantly however, these analyses reveal that while there were overall differences in the accuracy obtained for each alien name, self-referential encoding effects were consistently observed across each of these items and the learning of nonsense words was significantly improved by the simple application of a self-referential encoding intervention. Finally, we explored the relationship between sentence length and spelling performance. No significant relationship was found for the self group, $r(24)=.28, \mathrm{p}=.19$, or for the other encoding group, $r(23)=.11, \mathrm{p}=.62$.

Compared to other-referential encoding, self-referencing increased both task engagement (as indicated by sentence generation) and spelling performance (by more than 20\%). This finding is notable because the manipulation comprised a simple 
amendment to a standard pedagogical task, requiring no training or costly teaching materials. However, it is possible that the absence of any real knowledge about the unfamiliar other-referent (the alien Splay) may have contributed to the reported difference in the number of words written per sentence (see Bower \& Gilligan, 1979; Symons \& Johnston, 1997). A second experiment was therefore designed in which the other-referent was a character highly familiar in contemporary children's culture, J. K. Rowling's Harry Potter (see also Lombardo, Barnes, Wheelwright, \& BaronCohen, 2007; Pfeifer, Lieberman, \& Dapretto, 2007). The second experiment was also designed to more closely mirror classroom tasks to investigate the practicality of the manipulation, so children's learning of real vocabulary was assessed. A final feature of Experiment 2 was that a within-subjects design was employed to allow an exploration of any differential effects of self-referencing on pupils of varying verbal ability levels.

\section{EXPERIMENT 2}

To determine whether self-referencing would be readily applicable for employment as a teaching tool, Experiment 2 used a standard literacy task with 10 real words as the spelling materials. In line with SRE research paradigms, a familiar, non-intimate other-referent (i.e., Harry Potter) was used instead of a novel character (Bower \& Gilligan, 1979; Symons \& Johnston, 1997). Following the results of Experiment 1, it was predicted that self-referential encoding would result in longer sentence generation and higher spelling performance that other-referential encoding.

In addition, measures of verbal fluency (BPVS II - Dunn, Dunn, Whetton \& Burley, 1997) and phonological processing (CNRep - Gathercole et al., 1994) were 
included. These tests were selected to gauge aspects of verbal processing that could contribute to individual differences in literacy (Gathercole, 2006). We expected that children who perform at a lower level on these measures might benefit more from the additional encoding support provided by self-referential encoding.

\subsection{Method}

\subsubsection{Participants and design}

Thirty-two primary school children aged between 94 months and 109 months ( $M: 101.13$ months, $S D: 4.42,17$ females) participated in the experiment, which had a repeated measures (Referent: Self or Other) design. The children were recruited from one Year 4 class in three different Aberdeenshire primary schools. In each class the children were situated into four different spelling groups based on spelling ability. Each spelling group received words appropriate to their level of ability and to their current spelling goals. Therefore materials differed across groups and across participating schools. None of the children who took part in this study participated in Experiment 1 .

\subsubsection{Materials and procedure}

Testing took place over two weeks (one week per referent condition, order counter-balanced across participating classes). Prior to testing, the Experimenter was provided by classroom teachers with a list of 20 spelling words for each child (ten words for each week of testing). The content of spelling lists varied by class and spelling group (i.e., the spelling group to which each child was already assigned by the teacher, based on his/her ability). The spelling words provided by the teachers did 
not differ between self-and other-referent conditions in terms of word- or syllabiclength. (both $p s>.05$ ).

At the beginning of the school week each child was given a worksheet showing ten new spelling words (for example, came, same, gave, like, nine, five, joke, hope, rope, tube). These items were selected on the basis of weekly spelling or phonics objectives for each spelling group. The child was asked to copy each of these words three times, then to use each word in a self-generated sentence (i.e., write ten sentences). The effect of referent was manipulated by asking the children to begin their sentences with either "Harry..." (other-referent condition) or "I..." (self-referent condition). The order with which children undertook these two referent encoding tasks was counterbalanced across groups over the two week session, such that half of the groups undertook the self task first followed by the other task a week later, and half the participants had the opposite task order. Teachers understood the purpose of the experiment and did not provide any additional support to this task. The worksheet was completed in the classroom.

At the end of each week (i.e., four days after the encoding task), each child's spelling was tested individually. The Experimenter read out the ten spelling words learned that week and the child was asked to write each word on a worksheet, concentrating on the spelling.

\subsection{Results and Discussion}

Copying accuracy was high on this task (2.8\% error). As a result, all children were included in subsequent analyses. For illustration, example self-referent and other-referent sentences from two participants are listed below: 


\section{Participant A, aged 94 mths}

Self:

I like to sit down on a seat.

I have a sister and she is a teenager.

I got chased by a shark.

Other:

Harry was on a farm.

Harry had a belt.

Harry is one centimetre.

\section{Participant B, aged 104 mths}

Self:

I am good at jumping.

I like when its snowing.

I looked at a wall.

Other:

Harry saved Hogworts.

Harry pointed at me.

Harry was hiding from Voldermort.

This experiment used a male other-referent (Harry Potter). At the suggestion of an anonymous reviewer we included participant gender as a between subjects factor in our analysis of sentence length and spelling performance in each encoding condition.

For sentence length, we employed a mixed ANOVA and found a significant effect of gender, $F(1,30)=7.77, \mathrm{p}<.009, d=.48$, representing a medium effect, with girls writing significantly more words $(M: 6.19, S D: .21)$ in their sentences than boys (M: 5.34, SD: .24), but gender did not interact with encoding condition, $F(1,30)=.005$, $\mathrm{p}=.94$. As in Experiment 1, we observed a significant effect of encoding condition, $F(1,30)=4.26, \mathrm{p}<.048, d=.26$ representing a small effect, with self-referential sentences containing more words than other-referential outputs. (See Table 2). 
Spelling accuracy was also subjected to the same mixed ANOVA. Here we found a no significant effect of gender, $F(1,30)=2.27$, $\mathrm{p}=.14$, we also observed no significant interaction between gender and encoding condition $F(1,30)=.1 .98, \mathrm{p}=.17$. As in Experiment 1, we observed a significant effect of encoding condition on spelling performance, $F(1,30)=11.86, \mathrm{p}=.002, d=.238$ with words encoded in selfreferential manner spelled more accurately than those encoded under the otherreferent encoding condition (see Table 2). These findings replicate the pattern found in Experiment 1, suggesting that when the self-referencing manipulation is applied in a classroom context using real vocabulary, the same encoding advantage emerges.

The relationship between sentence length and spelling accuracy was explored, revealing no significant correlation between these factors $r(32)=.007, p=.97$. The absence of a linear relationship between writing performance and spelling accuracy suggests that spelling improvements are not produced by increased engagement alone. Previous research has indicated that self-relevant encoding tasks increase attentional processing and affective arousal (Bargh, 1982; Turk, van Bussel, Brebner et al., 2011), supporting memory increases for words and objects associated with self (Turk et al., 2008; Turk, van Bussel, Waiter \& Macrae, 2011). These low-level mechanisms may play an important role in increasing educational performance, especially in literacy tasks like spelling traditionally thought of as "boring" by a significant minority of children (Scottish Survey of Achievement: Reading and Writing 2009). This indicates that other elements of academic engagement not specifically measured here (i.e., the positive affect generated by task that represents emotional engagement) may offer better predictive power in relating engagement to outcomes using these self-referential encoding. 
Finally, individual differences were explored by calculating a self-referent encoding advantage score (i.e., other-referent performance subtracted from selfreferent performance) for both sentence generation and spelling by each child. Correlational analyses were conducted to determine whether individual differences in age verbal mental age (BPVS scores) or non-verbal working memory (CNRep scores) predicted the self-referent encoding advantage. No correlations approached significance, other than a marginal tendency for the effect of self-referencing on sentence generation to reduce with age, $r(32)=-.32, p=.075$, 2-tailed (see Table 3), suggesting that this manipulation may be more profitable for children earlier in earlier educational stages. The issue of which age group is most susceptible to the benefits of self-referential encoding should be the subject of future research, but existing SRE work suggests that the value of self-referencing is consistent in early childhood, then grows toward adult levels between 7 - 10 years (Cunningham et al., 2014; Halpin, Puff, Mason, \& Marston, 1984). This implies that a much wider age range may be appropriate for this sort of intervention. The absence of reliable relationships between individual difference measures and the size of the advantage for self-referenced words is difficult to interpret as materials were tailored to accommodate differences in ability (i.e., children were taught in different spelling groups). This should have the impact of maximizing performance across the ability range, and as the data show, approximately half of the participants in this study were at ceiling levels of spelling accuracy in the self-referential encoding condition (see Tables $2 \& 3$ ). 


\section{GENERAL DISCUSSION}

The findings of the current inquiry demonstrate the significant power of selfreferencing to enhance children's learning. The two experiments confirm that selfreferencing increases children's engagement in literacy tasks (as indicated by the number of words produced in children's sentences) and improves spelling accuracy for both nonsense and real words. Given that the only task manipulation was a verbal instruction to change the subject of each sentence, this study reveals a simple but effective mechanism to improve children's literacy that could easily be accommodated into current teaching practices.

The independence of the behavioural engagement and spelling performance in the current tasks also alludes to multiple mechanisms of self-support to learning new spelling words. The self is generally understood to operate through multiple routes, enhancing memory through increased attention and arousal (hence increased task engagement), but also by providing a familiar, easily accessible construct through which incoming information can be elaborated and organised (Klein \& Kihlstom, 1986, Klein \& Loftus, 1988; Symons \& Johnson, 1997, Turk et al, 2008; Turk, van Bussel, Brebner et al., 2011; Turk, van Bussel, Waiter et al., 2011), giving rise to rich, recollective retrieval from memory (Van den Bos, Cunningham, Conway \& Turk, 2010). In this regard, the self is not regarded as providing a 'special' route to enhanced encoding, although it may be especially efficient at eliciting these multiple routes (see Gillihan \& Farah, 2005). The extent to which some or all of these routes to memory enhancement are exploited by the current task is a potentially fruitful avenue of future research.

Reeve (2013) has suggested that agentic engagement may offer an additional mechanism to enhance motivation and learning outcomes. The self-efficacious 
(Bandura, 1997) agentic control of educational materials may provide an additional route through which self-referential encoding can provide a learning enhancement. Illustrating the relationship between self and agency, Cunningham et al. (2011) engaged participants in an ownership task in which they were able to view and choose objects for themselves or others. Personal choice elicited a greater memory bias for self-owned objects than when ownership was assigned by the experimenter. What is perhaps most interesting in this study is that even when participants made their choice blindly (i.e., by ticking numbers on a grid to correspond to items they would receive) the same effect of choice on memory was observed. In this way, the participant's perceived agentic control over the allocation of items to self also provided a boost to memory. One possibility for further research is that a similar act of choosing, whether blind or overt, could also offer a mechanism to increase agentic engagement in spelling tasks and further improve learning outcomes (see Patal, Cooper \& Wynn, 2010).

The current findings are presented as an initial test of an innovative intervention, raising many questions that need to be addressed by future research. For example, in the current study, the words used as stimuli were not systematically manipulated and did not have a high difficulty variance. Spelling performance was also skewed towards ceiling levels, perhaps contributing to the weak correlations between sentence length and spelling performance, as well as between the selfadvantage and individual differences in verbal ability and age. More rigorous memory tests would offer increased chances of finding relationships with individual differences. Further, sentence production was relatively short and in future, analysis of the quality of material generated by self- and other-referent instructions could be explored in longer outputs (e.g., aurally-presented stories rather than written 
sentences). It seems plausible that such outputs would reveal qualitative differences between responses generated by self- and other-cues, providing further insight into the mechanisms supporting improved spelling performance. Self-reported engagement would also be a useful measure. Furthermore, different levels of selfreferencing may also be engendered by different types of self-cues, the identification of which would allow more focused use of self-referencing in the classroom.

The learning benefits provided by self-referential encoding are unlikely to be limited to the improvements in spelling and writing identified in the current inquiry. We suggest that the current findings should be extended to assess the impact of selfreferencing across education, as similar manipulations could be applied to the whole range of knowledge learning, in both arts and sciences. The work of d'Ailly and colleagues (d'Ailly, Murray, \& Corkill, 1995; d'Ailly et al., 1997) showing that including self-referent terms improves performance on math tasks is indicative of this. d'Ailly et al. (1997) argue that self functions to decrease the cognitive load of the relational tasks, but there is no direct evidence of the route through which the self improves performance. The engagement argument expounded here may offer an additional explanation (Christenson et al., 2012; Fredericks et al., 2004).

While the experiments reported here indicate a self-referential encoding effect upon the learning of real and nonsense words, it may also be possible that the variance between learning materials (i.e., words and nonwords) may have additionally impacted the results (Clark, 1973; Quené \& Van den Bergh 2008). In the present study we did not have the statistical power to speak to this concern so it remains a key area to address in future work in this area. Additional work is also required to determine the long-term benefits of self-referencing, beyond the relatively short retention periods assessed in the current inquiry. Other forms of elaborative encoding 
can provide a long-term learning scaffold (Craik \& Lockhart, 1972; Thomas \& Wang, 1996), but this remains to be established for self-referencing specifically. Education often requires repeated exposure to learning materials, so the effects of repeated selfreferential encoding of to-be-learned information may further enhance its effectiveness.

\section{CONCLUSIONS}

In conclusion, the current study paves the way for future research on the efficacy of using self-referential learning tasks to enhance young children's learning. Together, the studies reported here demonstrate that applying the self in learning to spell enhances both engagement and retention of information in children, potentially providing a high-impact, cost neutral and valuable application of cognitive science to education. 
Table 1: Analysis of performance for each of the stimulus materials in Experiment 1. Standard error in parentheses.

\begin{tabular}{ccccc}
\hline $\begin{array}{c}\text { Alien } \\
\text { Name }\end{array}$ & $\begin{array}{c}\text { Self } \\
\text { Words }\end{array}$ & $\begin{array}{c}\text { Other } \\
\text { Words }\end{array}$ & $\begin{array}{c}\text { \% Self } \\
\text { Accuracy }\end{array}$ & $\begin{array}{c}\text { \% Other } \\
\text { Accuracy }\end{array}$ \\
\hline Genful & $9.83(4.33)$ & $7.67(2.51)$ & $91(29)$ & $71(46)$ \\
Winead & $9.65(3.08)$ & $7.92(2.89)$ & $56(50)$ & $41(50)$ \\
Arror & $9.65(3.45)$ & $8.29(3.80)$ & $91(29)$ & $71(46)$ \\
Swarty & $8.96(3.60)$ & $7.46(3.10)$ & $78(42)$ & $46(51)$ \\
\hline
\end{tabular}

Table 2: Descriptive statistics for group size, age, CNRep, sentence length, spelling accuracy and total number of participants at ceiling for each encoding group in Experiment 1, standard deviation in parentheses.

\begin{tabular}{lcccccc}
\hline $\begin{array}{l}\text { Encoding } \\
\text { Group }\end{array}$ & N & $\begin{array}{c}\text { Age } \\
\text { (Months) }\end{array}$ & $\begin{array}{c}\text { Standardized } \\
\text { CNRep } \\
\text { Score }\end{array}$ & $\begin{array}{c}\text { Mean } \\
\text { Words per } \\
\text { Sentence }\end{array}$ & $\begin{array}{c}\text { Mean \% } \\
\text { Spelling } \\
\text { Accuracy }\end{array}$ & $\begin{array}{c}\text { Number at } \\
\text { Ceiling } \\
\text { For Spelling }\end{array}$ \\
\hline Self & 24 & $97.96(6.54)$ & $105.75(2.17)$ & $9.68(2.53)$ & $77.08(27.50)$ & 11 \\
Other & 23 & $96.48(1.33)$ & $106.04(2.41)$ & $7.82(2.23)$ & $58.70(28.81)$ & 5 \\
\hline
\end{tabular}

Table 3: Means sentence length and spelling accuracy for each encoding condition, and total number of participants at ceiling in Experiment 2, standard deviation in parentheses.

\begin{tabular}{lccc}
\hline Encoding & $\begin{array}{c}\text { Words per } \\
\text { Condition }\end{array}$ & $\begin{array}{c}\text { Spelling } \\
\text { Accuracy } \\
\text { Sentence }\end{array}$ & $\begin{array}{c}\text { Number at } \\
\text { Ceiling on } \\
\text { Spelling Test } \\
(\mathbf{N}=32)\end{array}$ \\
\hline Self & $6.08(1.30)$ & $84.1(23.94)$ & 16 \\
Other & $5.51(1.16)$ & $74.4(23.81)$ & 10 \\
\hline
\end{tabular}

Table 4: Correlation coefficients and p-values (in parentheses) for the relationship between age in months, verbal fluency (BPVS) phonological processing ability (CNRep) and performance differences in sentence length and spelling performance

\begin{tabular}{lcccc}
\hline & BPVS Score & CN Rep Score & $\begin{array}{c}\text { Sentence } \\
\text { Difference }\end{array}$ & $\begin{array}{r}\text { Spelling } \\
\text { Difference }\end{array}$ \\
\hline Age in Months & $-.90(.623)$ & $-.239(.188)$ & $-.391(.075)$ & $-.045(.808)$ \\
BPVS Score & & $.380(.032)$ & $-.076,(.679)$ & $.086(.639)$ \\
CN Rep Score & & & $-.066(.719)$ & $-.094(.608)$ \\
Sentence Diff & & & & $.007(.969)$ \\
\hline
\end{tabular}




\section{REFERENCES}

Bandura, A. (1997) Self-efficacy: The exercise of control. New York NY: Freeman

Bargh, J. A. (1982). Attention and automaticity in the processing of self-relevant information. Journal of Personality and Social Psychology, 43, 425-436.

Bloodgood, J. W. (1999). What's in a name? Children's name writing and literacy acquisition. Reading Research Quarterly, 34, 342-367.

Both-de Vries, A. C., \& Bus, A. G. (2008). Name writing: A first step to phonetic writing? Does the name have a special role in understanding the symbolic function of writing? Literacy Teaching and Learning, 12, 37-55.

Both-de Vries, A.C., \& Bus, A.G. (2010). The proper name as starting point for basic reading skills. Reading and Writing, 23, 173-187

Bower, G. H., \& Gilligan, S. G. (1979). Remembering information related to one's self. Journal of Research in Personality, 13, 420-432.

Brown, R. (1973). A first language: The early stages. Cambridge, MA: Harvard University Press.

Christenson, S. L., Reschly, A., L., \& Wylie (Eds). (2012) The handbook of research on student engagement. New York NY: Springer

Clark, H. H. (1973). The language-as-fixed-effect fallacy: A critique of language statistics in psychological research. Journal of Verbal Learning and Verbal Behavior, 12, 335-359.

Craik, F. I. M. \& Lockhart, R. S. (1972). Levels of processing: A framework for memory research. Journal of Verbal Learning and Verbal Behavior, 11, 671684.

Conway, M. A. \& Dewhurst, S. A. (1995). The self and recollective experience. Applied Cognitive Psychology, 9, 1-19. 
Cunningham, S. J., Brebner, J. L., Quinn, F., \& Turk, D. J. (2014). The self-reference effect on memory in early childhood. Child Development, 85, 808-823

Cunningham, S. J. Turk, D. J., Macdonald, L. M. \& Macrae, C. N. (2008). Yours or mine? Ownership and memory. Consciousness and Cognition, 17, 312-318.

Cunningham, S. J., Van den Bos, M., \& Turk, D. J. (2011). Exploring the effects of ownership and choice on self-memory biases. Memory, 19, 449-461

Cunningham, S. J., Vergunst, F., Macrae, C.N., \& Turk, D. J. (2013). Exploring early self-referential memory effects through ownership. British Journal of Developmental Psychology, 31, 289-301

d'Ailly, H., Murray, H. G., \& Corkill, A. (1995). The cognitive effects of selfreferencing. Journal of Contemporary Educational Psychology, 20, 88-113.

d'Ailly, H. H., Simpson, J., \& MacKinnon, G. E. (1997). Where should “you” go in a math compare problem? Journal of Educational Psychology, 89, 562-567.

Davis-Dorsey, J., Ross, S. M., \& Morrison, G. R. (1991). The role of rewording and context personalization in the solving of mathematical word problems. Journal of Educational Psychology, 83, 61-68.

Dunn, L. M., Dunn, L. M., Whetton, C., \& Burley, J. (1997). The British Picture Vocabulary Scale (2 $2^{\text {nd }}$ Ed.). London: National Foundation for Education Nelson.

Eccles, J. S., Wigfield, A., \& Schiefele, U. (1998). Motivation to succeed. In W. Damon (Series Ed.) \& N. Eisenberg (Volume Ed.) Handbook of child psychology (5th ed., Vol. III, pp. 1017-1095). New York: Wiley.

Fairbairn, D. M. (1993). Creating story problems. Arithmetic Teacher, 41, 140-142. 
Fredricks, J. A., Blumenfeld, P. C., \& Paris, A. H. (2004). School engagement: Potential of the concept, state of the evidence. Review of Educational Research, 74, 59-109.

Gathercole, S. E. (2006) Nonword repetition and word learning: The nature of the relationship. Applied Psycholinguistics 27, 513-543

Gathercole, S. E., Willis, C. E., Baddeley, A. D. \& Emslie, H. (1994). The children's test of nonword repetition: A test of phonological working memory. Memory, 2, 103-127.

Gillihan, S. J.; Farah, M. J. (2005). Is Self Special? A critical review of evidence from experimental psychology and cognitive neuroscience. Psychological Bulletin, 131, 76-97.

Giordano, G. (1990). Strategies that help learning-disabled studentssolve verbal mathematical problems. Preventing School Failure, 35, 24-28.

Halpin, J. A., Puff, C. R., Mason, H. F., \& Marston, S. P. (1984). Self-reference encoding and incidental recall by children. Bulletin of the Psychonomic Society, 22, 87-89.

Hart, J. M. (1996). The effect of personalized word problems. Teaching Children Mathematics, 2, 504-505.

Klein, S. B., \& Kihlstrom, J. F. (1986). Elaboration, organization, and the selfreference effect in memory. Journal of Experimental Psychology: General, 115, 26-38.

Klein, S. B., \& Loftus, J. (1988). The nature of self-referent encoding: The contribution of elaborative and organizational processes. Journal of Personality and Social Psychology, 55, 5-11. 
Levin, I., Both-de Vries, A. C., Aram, D., \& Bus, A. G. (2005). Writing starts with own name writing: From scribbling to conventional spelling in Israeli and Dutch children. Applied Psycholinguistics, 26, 463-477.

Lewis, M. (2003) The emergence of consciousness and its role in human development. Annals of the New York Academy of Science, 1001, 104-133.

Lombardo, M. V., Barnes, J. L., Wheelwright, S. J., \& Baron-Cohen, S. (2007) Selfreferential cognition and empathy in autism. PLoS ONE 2(9): e883.

Meece, J. L., Blumenfeld, P. C., \& Hoyle, R. H. (1988). Students' goal orientation and cognitive engagement in classroom activities. Journal of Educational Psychology, 80, 514-523.

Mood, D. M., (1979) Sentence comprehension in preschool children: Testing an adaptive egocentrism hypothesis. Child Development, Vol. 50, No. 1, pp. 247250

Newmann, F., Wehlage, G. G., \& Lamborn, S. D. (1992). The significance and sources of student engagement. In F. Newmann (Ed.), Student engagement and achievement in secondary schools (p. 11- 39). New York NY: Teachers College Press.

Nuttin, J. M. (1985). Narcissism beyond Gestalt and awareness: The name letter effect. European Journal of Social Psychology, 15, 353-361.

Paivio, A. (1986). Mental representations: A dual coding approach. New York: Oxford University Press.

Parker, M. D. (2005) A comparative study between mean length of utterance in morphemes (MLUm) and mean length of utterance in words (MLUw). First Language, 25, 365-376. 
Patall, E. A., Cooper, H., \& Wynn, S. R. (2010) The effectiveness and relative importance of choice in the classroom. Journal of Educational Psychology, $102,896-915$.

Pfeifer J. H., Lieberman, M. D., \& Dapretto, M. (2007) “I know what you are but what am I?!'”: Neural bases of self- and social knowledge retrieval in children and adults. Journal of Cognitive Neuroscience 19, 1323-1337.

Pressley, M., Borkwski, J. G., \& Schneider, W. (1989). Good information processing: What it is and how education can promote it. International Journal of Education Research, 13, 857-867.

Pressley, M., Levin, J. R., Kuiper, N. A., Bryant, S. L., \& Michener, S. (1982). Mnemonic versus nonmnemonic vocabulary-learning strategies: Additional comparisons. Journal of Educational Psychology, 74, 693-707.

Quené, H., \& Van den Bergh, H. (2008). Examples of mixed-effects modeling with crossed random effects and with binomial data. Journal of Memory and Language, 59, 413-425.

Reeve, J. (2013) How students create motivationally supportive learning environments for themselves: The concept of agentic engagement. Journal of Educational Psychology, 105, 579-595.

Ross, J., Anderson, J. R., \& Campbell, R. N. (2011). I remember me: Mnemonic selfreference effects in preschool children. Monographs of the Society for Research in Child Development, 76, 1-102.

Rogers, T. B., Kuiper, N.A., \& Kirker, W.S. (1977). Self-reference and the encoding of personal information. Journal of Personality and Social Psychology, 35, $677-688$. 
Sadoski, M. (2001). Resolving the effects of concreteness on interest, comprehension, and learning important ideas from text. Educational Psychology Review, 13, 263-281.

Sadoski, M., Goetz, E. T., \& Fritz, J. (1993). A causal model of sentence recall: Effects of familiarity, concreteness, comprehensibility, and interestingness. Journal of Reading Behaviour, 25, 5-16.

Sadoski, M., Goetz, E. T., \& Rodriguez, M. (2000). Engaging texts: Effects of concreteness on comprehensibility, interest, and recall in four text types. Journal of Educational Psychology, 92, 85-95.

Scottish Survey of Achievement: Reading and Writing (2009). Scottish Government: http://www.scotland.gov.uk/Resource/Doc/303481/0095146.pdf

Sui, J. \& Zhu, Y. (2005). Five-year-olds can show the self-reference advantage. International Journal of Behavioral Development, 29, 382-387.

Symons, C. S., \& Johnson, B. T. (1997). The self-reference effect in memory: A meta-analysis. Psychological Bulletin, 121, 371-394.

Thomas, M. H. \& Wang, A. Y. (1996). Learning by the keyword method: Looking for long-term benefits. Journal of Experimental Psychology: Applied, 2, 330-342.

Treiman, R., Kessler, B., \& Bourassa, D. (2001). Children's own names influence their spelling. Applied Psycholinguistics, 22, 555-570.

Turk, D. J., Cunningham, S. J, \& Macrae, C. N. (2008). Self-memory biases in explicit and incidental encoding of trait adjectives. Consciousness and Cognition, 17, 1040-1045.

Turk, D. J., van Bussel, K., Brebner, J. L., Toma, A., Krigolson, O., \& Handy, T. C. (2011) When IT becomes MINE: Attentional biases triggered by object ownership. Journal of Cognitive Neuroscience, 23, 3725-3733. 
Turk, D. J., van Bussel, K., Waiter G. D., \& Macrae, C. N. (2011) Mine and me: Exploring the neural basis of object ownership. Journal of Cognitive Neuroscience, 23, 3657-3668.

Van den Bos, M., Cunningham, S. J., \& Turk, D. J. (2010). Mine to remember: The effects of minimal ownership on remembering and knowing. Quarterly Journal of Experimental Psychology, 63, 1065-1071.

Wigfield, A., Eccles, J. S., Schiefele, U., Roeser, R., \& Davis-Kean, P. (2006). Development of achievement motivation. In W. Damon (Series Ed.) \& N. Eisenberg (Volume Ed.), Handbook of child psychology, 6th Ed. Vol.3. Social, emotional, and personality development (pp. 933-1002). New York NY: John Wiley. 